\title{
EVALUASI PENCAPAIAN LABA PADA HOTEL SAHID KAWANUA MANADO DENGAN MENGGUNAKAN ANALISIS COST VOLUME PROFIT (CVP)
}

\author{
Aristion Bunga $^{1}$, Ventje Ilat ${ }^{2}$, Dhullo Afandy $^{3}$ \\ ${ }^{1,2,3}$ Jurusan Akuntansi, Fakultas Ekonomi dan Bisnis Universitas Sam Ratulangi, Jl. Kampus Bahu, Manado, \\ 95115, Indonesia
}

E-mail : aristobunga182@gmail.com

\begin{abstract}
The problem in this research is how to evaluate the achievement of profit by using cost volume profit analysis (CVP) at Hotel Sahid Kawanua Manado, with the starting point from the backgound of competition and growth of hotels that increasingly mushrooming in Manado city. This study aims to determine the calculation and profit planning at Hotel Sahid Kawanua Manado by using sales operational data by using cost volume profit analysis (CVP) for multi product in 2015-2017, and to determine Break Even Point (BEP), profit planning and find out what level of margin of safety (minimum selling rate of company not to suffer losses) in year 2015-2017. The data used comes from literature study, observation and interview on the object of research. This data processing uses the help of Microsoft Excel 2016 program to perform the separation of semivariable costs into fixed costs and variable costs. Besed on the calculation of cost volume profit analysis (CVP), showed that Hotel Sahid Kawanua Manado has done the evaluation of the achievement of earnings well seen from the level of profit generated and the level of margin of safety is increasinng from year to year. Keywords : Cost Accounting, Cost Volume Profit Analysis (CVP), Earnings Achievement
\end{abstract}

\section{PENDAHULUAN}

Era globalisasi yang penuh dengan tantangan dan rintangan dalam dunia usaha ada di depan mata. Hal ini membuat persaingan bisnis semakin sulit, terutama bagi perekonomian negara kita yang masih terus terguncang perekonomiannya. Untuk menjaga keseimbangan hidup perusahaan dalam menghadapi persaingan yang ketat tersebut diperlukan penanganan dan pengelolahan yang baik. Manajer hendaknya dapat berfikir kritis dalam mengambil setiap keputusan agar dapat membawa dampak yang baik bagi perkembangan perusahaan. Dalam mencapai tujuan perusahaan tersebut, terdapat hubungan antara biaya pemasaran, volume penjualan, dan laba.

Menurut Wiyasha (2014:200) Cost Volume Profit (CVP) merupakan alat analisis bantu manajemen yang menyatakan hubungan antar berbagai tingkat biaya, volume, dan harga jual. Analisis Cost Volume Profit dapat membantu manajer dalam memahami perilaku total biaya, total pendapatan, dan laba operasi saat perubahan terjadi dalam tingkat keluaran, harga jual, biaya variabel atau biaya tetap. Evaluasi yang baik dapat membantu dalam penaksiran tingkat laba yang akan didapat perusahaan, sehingga laba yang didapat akan lebih optimal. Untuk mencapai laba yang optimal (dalam perencanaan laba maupun realisasi), manajer dapat menggunakan langkah-langkah berikut:

1. Menekan biya operasional serendah mungkin dengan mempertahankan tingkat harga jual dan volume penjualan yang ada.

2. Menentukan tingkat harga jual sedemikian rupa sesuai dengan laba yang dikehendaki.

3. Meningkatkan volume penjualan sebesar mungkin.

Analisis cost volume profit (CVP) dapat juga digunakan pada industri jasa, misalnya industri perhotelan. Dalam industri perhotelan, perusahaan dituntut bagaimana menghasilkan dan memasarkan berbagai jasa yang terdapat pada hotel tersebut bagi konsumen yang 
membutuhkannya. Pendapatan industri perhotelan dipengaruhi oleh barbagai faktor, salah satunya adalah tingkat kepadatan hunian.

Analisis break even point adalah suatu kegiatan perusahaan dalam kondisi tidak mendapat laba maupun menderita rugi. Laba merupakan selisih antara penjualan dan biayabiaya. Salah satu faktor penting yang dapat mempengaruhi dalam pengambilan keputusan tersebut adalah faktor biaya yang selama satu periode kerja adalah tetap jumlahnya, dan tidak mengalami perubahan. Biaya variabel merupakan biaya yang dipengaruhi oleh perubahan volume produksi atau penjualan.

Biaya yang dipertimbangkan dalam pengambilan keputusan oleh manajemen disebut sebagai biaya relevan. Biaya relevan (relevant cost) adalah biaya yang terjadi pada masa yang akan datang dan berbeda antara alternatif yang sedang dipertimbangkan dalam suatu keputusan. Jadi sangat penting bagi seorang manajer untuk mengetahui break even point perusahaan yang dipimpinnya. Dengan mengetahui break even point (titik impas) manajer perusahaan juga dapat menargetkan atau merencanakan jumlah penjualan produk agar memperoleh keuntungan tertentu.

Hotel Sahid Kawanua Manado merupakan salah satu hotel berbintang tiga yang cukup terkenal di kota Manado Provinsi Sulawesi Utara yang memiliki daya tarik tersendiri bagi penulis untuk dijadikan objek sebagai penelitian dalam penulisan skripsi ini. Hotel Sahid Kawanua Manado merupakan suatu perusahaan yang bergerak di bidang jasa penjualan kamar, meeting room, room service dll.

\section{TINJAUAN PUSTAKA}

\subsection{Akuntansi Manajemen}

Menurut Samryn (2013:4) akuntansi manajemen merupakan bidang akuntansi yang berfokus pada penyediaan, termasuk pengembangan dan penafsiran informasi akuntansi bagi para manajer untuk digunakan sebagai bahan perencanan, pengendalian operasi dan dalam pengambilan keputusan. Akuntansi manajemen berhubungan dengan informasi mengenai perusahaan untuk memberikan manfaat bagi mereka yang berada dalam perusahaan.

\subsection{Akuntansi Biaya}

Bustami dan Nurlela (2013:3), akuntansi biaya merupakan satu bidang akuntansi, merupakan bagian dari akuntansi keuangan yang saling berhubungan dalam sistem pelaporan, dan pengambilan keputusan manajemen. Mulyadi (2015:7), mengatakan akuntansi biaya adalah proses pencatatan, penggolongan, peringkasan dan penyajian biaya pembuatan dan penjualan produk atau jasa dengan cara-cara tertentu, serta penafsiran terhadapnya. Siregar (2014:10), mengungkapkan bahwa akuntansi biaya didefinisikan sebagai proses pengukuran, penganalisisian, perhitungan dan pelaporan biaya, profitabilitas, dan kinerja operasi.

\subsection{Pengertian Biaya (cost)}

Menurut Baldric,et.al (2013:23), biaya adalah penggorbanan sumber ekonomi untuk memperoleh barang atau jasa yang diharapkan memberi manfaat sekarang atau masa yang akan datang. Menurut Hansen dan Mowen (2015:45) biaya adalah kas atau nilai setara kas yang dikorbankan untuk mendapatkan barang atau jasa yang diharapkan memberi manfaat saat ini atau di masa depan bagi organisasi.

\subsection{Klasifikasi Biaya}

Menurut Mulyadi (2014:13), biaya dapat diklasifikasikan ke dalam lima macam penggolongan biaya yaitu:

1. Penggolongan biaya menurut objek pengeluaran

2. Penggologan biaya menurut fungsi pokok dalam perusahaan

3. Penggolongan biaya menurut hubungan biaya dengan sesuatu yang dibiayai

4.Penggolongan biaya menurut perilaku biaya dalam hubungannya dengan perubahan volume kegiatan 
5. Penggolongan biaya atas dasar jangka waktu manfaatnya

\subsection{Perilaku Biaya}

Menurut Baldric Siregar (2013:73) perilaku biaya adalah pola yang menggambarkan bagaimana jumlah biaya bervariasi atas perubahan aktivitas bisnis. Berdasar perilakunya dengan hubungan dengan volume kegiatan biaya dapat dibagi menjadi tiga, yaitu :

1. Biaya Tetap

2. Biaya Variabel

3. Semivariabel/Biaya Campuran

\subsection{Analisis Cost Volume Profit (CVP)}

Wiyasha (2014:200) Cost Volume Profit (CVP) merupakan alat analisis manajemen yang menyatakan hubungan antar berbagai tingkat biaya, volume, dan harga jual. Cost volume Profit $(C V P)$ dengan demikian merupakan alat manajemen untuk mempredikisi tingkat laba perusahaan bila biaya dan volume bisnis pada tingkat tertentu.

\subsection{Analisis Titik Impas (Break Even Point)}

Menurut Kasmir (2013:333) Analisis titik impas adalah suatu keadan di mana perusahaan beroperasi dalam kondisi tidak memperoleh pendapatan (laba) dan tidak pula menderita kerugian. Artinya dalam kondisi ini jumlah oendapatan yang diterima sama dengan jumlah biaya yang dikeluarkan. Lebih lanjut analisis ini digunakan untuk menentukan berapa unit yang harus terjual agar kita memperoleh keuntungan, baik dalam volume penjualan dalam unit maupun rupiah.

\subsection{Konsep Bauran Produk}

Kebanyakan perusahaan memiliki banyak produk dan seringkali produk tersebut tidak mencetak laba yang sama. Jadi laba akan lebih besar jika barang dengan margin tinggi yang memiliki proporsi yang relatif besar dalam total penjualan.

Perubahan dalam bauran produk dari barang yang memiliki margin rendah akan menyebabkan total laba menurun walapun total penjualan mungkin meningkat. Sebaliknya, perubahaan dalam bauran produk dari barang yang memiliki margin rendah ke barang yang ber margin tinggi akan menyebabkan efek yang sebaliknya, total laba mungkin meningkat walaupun total penjualan menurun.

\subsection{Analisis Target Laba (Perencanaan Laba)}

Untuk mencapai laba yang besar manajemen dapat menempuh berbagai langkah, misalnya:

1. Menekan biaya produksi maupun biaya operasi serendah mungkin dengan mempertahankan tingkat harga jual dan volume penjualan yang ada.

2. Menentukan harga jual sedemikian rupa sesuai dengan laba yang diinginkan.

3. Meningkatkan volume penjualan sebesar mungkin.

Rumus biaya volume laba dapat digunakan untuk menentukan volume penjualan yang dibutuhkan untuk mencapai target laba. Menurut L.M. Samryn (2012:179), ada dua cara untuk melakukan analisis target laba, yaitu:

1. Metode Persamaan

Menghitung target penjualan dalam unit:

Penjualan = Biaya Variabel + Biaya Tetap + Laba

Menghitung target penjualan dalam rupiah:

Rasio Penjulan $=$ Rasio Margin Kontribusi + Biaya Tetap + Laba

2. Metode Margin Kontribusi

Penjualan dalam unit $=($ Biaya Tetap + Target Laba $) /$ Margin Kontribusi per unit

Penjualan dalam rupiah $=($ Biaya Tetap + Target Laba $) /$ Rasio Margin Kontribusi 


\subsection{Analisis Sensitivitas Perubahan Faktor-Faktor yang Mempengaruhi Laba}

Analisis hubungan biaya volume laba dapat dipakai oleh manajemen untuk menghadapi berbagai kemungkinan perubahan kondisi yang dapat mempengaruhi laba perusahaan. Menurut Mulyadi (2014:513) faktor-faktor yang mempengaruhi laba adalah:

1. Biaya

2. Harga Jual

3. Volume Penjualan dan Produksi

\section{METODE PENELITIAN}

Jenis data yang digunakan dalam penelitian ini adalah :

1. Data Kuantitatif yaitu data yang berupa angka-angka seperti penjualan, biaya-biaya yang dikeluarkan dan harga jual.

2. Data kualitatif yaitu data yang bukan berupa angka, sifatnya menunjang data kuantitatif sebagai keterangan seperti sejarah tentang perusahaan, struktur organisasi perusahaan, dan kegiatan-kegiatan dalam perusahaan selama priode 2015-2017

Sumber data yang diperoleh yaitu data primer, data yang didapat secara langsung dari objek yang diteliti guna mendapatkan data yang relavan dan dapat dipertanggungjawabkan kebenarannya. Data primer ini dilakukan dengan cara: wawancara, observasi, dan dokumentasi.

Metode analisis data yang digunakan dalam penelitian ini yaitu :

1. Mengklasifikasi semua biaya-biaya yang dikeluarkan kedalam biaya variabel (variabel cost) dan biaya tetap (fixed cost)

2. Metode analisis kuadrat terkecil untuk memisahkan biaya semivariabel menjadi biaya tetap dan biaya variabel dan menggunakan bantuan program Microsoft Excel 2016 dalam melakukan pemisahan biaya tersebut. Metode ini mengistimasi suatu hubungan linier didasarkan pada persamaan:

$\mathrm{Y}=\mathrm{a}+\mathrm{bx}$

$\mathrm{b}=\frac{\mathrm{n}\left(\sum \mathrm{XY}\right)-\left(\sum \mathrm{X}\right)\left(\sum \mathrm{Y}\right)}{\mathrm{n}\left(\sum \mathrm{X}^{2}\right)-\left(\sum \mathrm{X}\right)^{2}}$

$\mathrm{a}=\frac{\left(\sum \mathrm{Y}\right)-\mathrm{b}\left(\sum \mathrm{X}\right)}{\mathrm{n}}$

Dimana:

$\mathrm{X}=$ tingkat aktivitas

$\mathrm{Y}=$ total biaya semi variable

$\mathrm{a}=$ total biaya tetap

$\mathrm{b}=$ biaya variabel per unit aktivitas

$\sum=$ jumlah total observasi

3. Break Even Point (Titik Impas), untuk mendapat suatu keadaan dimana perusahaan tidak memperoleh keuntungan dan tidak mengalami kerugian baik dalam jumlah produk (kuantitas) maupun dalam rupiah.

$\mathrm{BEP}($ Rupiah $)=\frac{\mathrm{FC}}{1-\mathrm{VC} / \mathrm{S}}$

$\mathrm{BEF}($ Unit $)=\frac{\mathrm{FC}}{\mathrm{P}-\mathrm{VC}}$

dimana:

$\mathrm{FC}=$ Fixed Cost (biaya tetap)

$\mathrm{VC}=$ Variabel Cost (biaya variabel per unit) 
$\mathrm{S}=$ Volume Penjualan

$\mathrm{P}=$ Harga Jual Per unit

4. Analisis perencanaan laba adalah analisis yang memperliahatkan besarnya volume dari laba yang diinginkan. Rumus perhitungan perencanaan laba adalah sebagai berikut:

Penjualan $=\frac{\mathrm{FC}+\mathrm{Laba}}{1-\mathrm{VC} / \mathrm{s}}$

Margin of Safety (MoS) dapat dihitung dengan rumus :

MOS $($ rupiah $)=$ Total Penjualan - Penjualan Impas

Pengaman penjualan dapat juga dinyatakan dalam rupiah atau dalam bentuk prosentase, seperti pada rumus berikut : MOS $(\%)=\operatorname{MOS}($ Rupiah $) /$ Penjualan X $100 \%$

\section{HASIL ANALISIS DAN PEMBAHASAN}

\subsection{Hasil analisis}

Volume Operasional Penjualan Kamar Hotel

Volume operasional penjualan kamar pada hotel Sahid Kawanua Manado, pada tahun 2015 2017 dalam rupiah adalah sebagai berikut:

\section{Tabel 1}

Volume Operasional Penjualan Kamar Sahid Kawanua Manado Tahun 2015-2017

\begin{tabular}{|l|c|c|c|}
\hline \multicolumn{1}{|c|}{ Jenis Kamar } & \multicolumn{3}{|c|}{ Tahun } \\
\hline & $\mathbf{2 0 1 5}$ & $\mathbf{2 0 1 6}$ & $\mathbf{2 0 1 7}$ \\
\hline Superior Single & $99,907,653$ & $96,431,289$ & $99,291,492$ \\
\hline Superior Double & $96,097,869$ & $98,475,300$ & $102,940,812$ \\
\hline Delux Single & $242,608,490$ & $243,674,900$ & $244,670,800$ \\
\hline Delux Double & $120,750,435$ & $121,870,528$ & $172,914,925$ \\
\hline Junior Suite & $245,647,800$ & $246,964,200$ & $251,490,000$ \\
\hline Kawanua Suite & $442,608,490$ & $360,890,079$ & $390,872,429$ \\
\hline
\end{tabular}

Sumber : Hotel Sahid Kawanua Manado

Total keseluruhan jenis kamar jika diperhitungkan dalam satuan rupiah pada tahun 2015 sebesar Rp. 1,605,111,256 pada tahun 2016 sebesar Rp. 1,378,827,202, dan pada tahun 2017 sebesar Rp. 1,478,143,329

\section{Volume Biaya}

Hotel Sahid Kawanua Manado membutukan biaya-biaya guna kelancaran operasionalnya. Biaya-biaya yang terjadi selama tahun 2015-2017 adalah sebagai berikut: 
Tabel 2 Biaya - Biaya yang Terjadi pada Hotel Sahid Kawanua Manado Tahun 2015

\begin{tabular}{|l|r|}
\hline \multicolumn{1}{|c|}{ Biaya - Biaya } & Jumlah \\
\hline Biaya Operasional & $232,196,417$ \\
\hline Biaya Perlengkapan Hotel & $340,539,131$ \\
\hline Biaya Peralatan dan Perbaikan & $134,690,571$ \\
\hline Biaya Depresiasi Gedung & $88,338,979$ \\
\hline Gaji dan Upah & $66,689,602$ \\
\hline Fax, Telepon, Internet & $251,804,202$ \\
\hline Biaya Listrik & $56,607,735$ \\
\hline Jamsostek & $50,451,342$ \\
\hline Hadiah/Bonus & $47,890,760$ \\
\hline Biaya Kitchen Set & $97,213,551$ \\
\hline Biaya Pemasaran & $190,607,735$ \\
\hline Biaya Administrasi dan Umum & $382,733,400$ \\
\hline Biaya penyusutan dan Amortisasi & $129,147,769$ \\
\hline Biaya Departement Lainnya & $60,500,000$ \\
\hline Biaya Oli/Solar $\quad$ Total Biaya & $\mathbf{2 , 1 2 9 , 4 1 1 , 1 9 4}$ \\
\hline
\end{tabular}

Sumber: Hotel Sahid Kawanua Manado

Total keseluruhan volume biaya hotel tahun 2015 yang terdiri dari beberapa akun jika dihitung dalam satuan rupiah sebesar Rp. 2,129,411,194.

\subsection{Pembahasan}

\subsection{Evaluasi Tingkat Penjualan Minimal Untuk Memperoleh Laba}

Evaluasi tingkat penjualan minimal untuk mendapatkan tngkat penjualan minimal akan menggunakan rumus modifikasi BEP, dengan menambahkan laba dengan biaya tetap. Selanjutnya akan digunakan rumus margin of safety (MOS) untuk melihat, mengevaluasi tingkat kepekaan tingkat penjualan.

1. Tingkat penjualan minimal untuk laba pada Hotel Sahid Kawanua Manado tahun 2015 dapat diketahui dengan menggunakan rumus:

$$
\begin{aligned}
& \text { Penjualan }=\quad \text { FC }+ \text { Keuntungan } \\
& \text { 1- VC/s }
\end{aligned}
$$

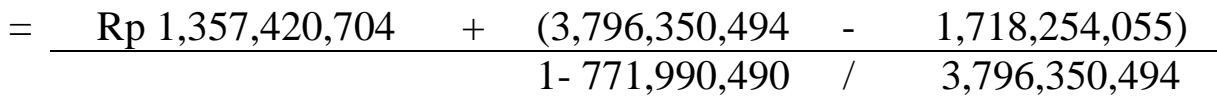

$$
\begin{aligned}
& =\frac{3,435,517,143}{0.79} \\
& =\operatorname{Rp} 4,348,755,877
\end{aligned}
$$

Jadi tingkat penjualan minimal untuk memperoleh laba tahun 2015 adalah Rp 4,348,755,877. Margin Of Safety (tingkat keamanan) penjualan pada Hotel Sahid Kawanua Manado untuk tahun 2015 yaitu sebagai berikut :

Margin Penjualan $_{(\mathrm{Rp})}=$ Total Penjualan - Penjualan Impas

$$
\begin{aligned}
& =\operatorname{Rp} 3,796,350,494-\operatorname{Rp~1,718,254,055~} \\
& =\operatorname{Rp} 2,078,096,439
\end{aligned}
$$

Jika dinyatakan dalam prosentase, maka

Presentase Penjualan $(\%)=\underline{\text { Margin penjualan dalam rupiah }}$

Penjualan 


$$
\begin{aligned}
& =\frac{3,796,350,494-1,718,254,055}{3,796,350,494} \\
& =\frac{2,078,096,432 \times 100 \%}{3,796,350,494} \\
& =54,73 \%
\end{aligned}
$$

Dari hasil perhitungan di atas diperoleh tingkat margin of safety sebesar 54,73\% yang berarti bahwa pada tingkat penjualan dan struktur biaya yang ada, jumlah maksimum penurunan target pendapatan penjualan yang tidak menyebabkan perusahaan mengalami kerugian adalah Rp 2,078,096,439.

2. Tingkat penjualan minimal untuk laba pada Hotel Sahid Kawanua Manado tahun 2016 dapat diketahui dengan menggunakan rumus:

$$
\begin{aligned}
& \text { Penjualan }=\frac{\mathrm{FC}+\text { Keuntungan }}{\text { 1- VC/s }} \\
& =\frac{\mathrm{Rp} 1,095,677,376+(4,616,050,431-1,274,043,460)}{1-629,316,665 / 4,611,050,431} \\
& =\frac{4,437,684,347}{0.86} \\
& =\text { Rp. 5,160,098,077 }
\end{aligned}
$$

Jadi tingkat penjualan minimal untuk memperoleh laba tahun 2016 adalah Rp $5,160,098,077$

Margin Of Safety (tingkat keamanan) penjualan pada Hotel Sahid Kawanua Manado untuk tahun 2016 yaitu sebagai berikut :

Margin Penjualan $_{(\mathrm{Rp})}=$ Total Penjualan - Penjualan Impas

$$
\begin{aligned}
& =\operatorname{Rp} 4,616,050,431-\operatorname{Rp~1,274,043,460} \\
& =\operatorname{Rp} 3,342,006,971
\end{aligned}
$$

Jika dinyatakan dalam prosentase, maka

Presentase Penjulan $(\%)=\underline{\text { Margin penjualan dalam rupiah }}$

$$
\begin{aligned}
& \text { Penjualan } \\
& =\frac{4,616,050,431-1,274,043,460}{4,616,050,431} \\
& =\frac{3,342,006,971 \times 100 \%}{4,616,050,431} \times 10 \\
& =72,39 \%
\end{aligned}
$$

Dari hasil perhitungan di atas diperoleh tingkat margin of safety sebesar $72,39 \%$ yang berarti bahwa pada tingkat penjualan dan struktur biaya yang ada, jumlah maksimum penurunan target pendapatan penjualan yang tidak menyebabkan perusahaan mengalami kerugian adalah Rp 3,342,006,971

3. Tingkat penjualan minimal untuk laba pada Hotel Sahid Kawanua Manado tahun 2017 dapat diketahui dengan menggunakan rumus:

$$
\begin{aligned}
& \text { Penjualan }=\frac{\mathrm{FC}+}{\mathrm{VC} / \mathrm{s}} \\
& =\frac{\operatorname{Rp~890,449,724}+(3,964,268,375-1,290,506,486)}{1-1,247,421,325 / 3,964,268,375} \\
& =\frac{3,564,211,613}{0.68} \\
& \text { Rp 5,241,487,666 }
\end{aligned}
$$


Jadi tingkat penjualan minimal untuk memperoleh laba tahun 2017 adalah Rp 5,241,487,666 Margin Of Safety (tingkat keamanan) penjualan pada Hotel Sahid Kawanua Manado untuk tahun 2017 yaitu sebagai berikut :

Margin Penjualan $_{(\mathrm{Rp})}=$ Total Penjualan - Penjualan Impas

$$
\begin{aligned}
& =\operatorname{Rp} 3,964,268,375-\operatorname{Rp} 1,290,506,486 \\
& =\operatorname{Rp} 2,673,761,889
\end{aligned}
$$

Jika dinyatakan dalam prosentase, maka

Presentase Penjulan $(\%)=\underline{\text { Margin penjualan dalam rupiah }}$

$$
\text { Penjualan }
$$

$$
\begin{aligned}
& =\frac{3,964,268,375-1,290,506,486}{3,964,268,375} \\
& =\frac{2,673,761,889}{3,964,268,375} \times 100 \% \\
& =67,44 \%
\end{aligned}
$$

Dari hasil perhitungan di atas diperoleh tingkat margin of safety sebesar $67,44 \%$ yang berarti bahwa pada tingkat penjualan dan struktur biaya yang ada, jumlah maksimum penurunan target pendapatan penjualan yang tidak menyebebkan perusahaan mengalami kerugian adalah $\operatorname{Rp} 2,673,761,889$

\section{KESIMPULAN DAN SARAN}

\subsection{Kesimpulan}

Berdasarkan analisis yang telah dilakukan terhadap data Hotel Sahid Kawanua Manado maka diperoleh beberapa kesimpulan sebagai berikut :

a. Hotel Sahid Kawanua Manado mengalami kenaikan laba pada tiap tahunnya mulai dari tahun 2015 hingga 2017. Laba yang diperoleh Hotel Sahid Kawanua Manado pada tahun 2015 yaitu $R p$ 1,666,939,300 dan laba tahun 2016 meningkat menjadi Rp 2,891,056,390. Laba tahun 2017 mengalami penurunan dari tahun sebelumnya sebesar Rp 1,826,397,326. Dari pembicaraan dari pihak yang terkait, disebutkan bahwa laba tidak mengalami kenaikan dikarenakan adanya perbaikan (renovasi) hotel tersebut.

b. Hotel Sahid Kawanua Manado telah menetapkan besarnya evaluasi tingkat penjualan untuk memperoleh laba dari tahun ke tahun berbeda dengan tahun berikutnya. Perbedaan ini disebabkan karena adanya renovasi Gedung hotel pada tahun 2017 yang menyebabkan kurangnya jumlah pengunjung dan besarnya biaya yang dikeluarkan pada hotel. Tahun

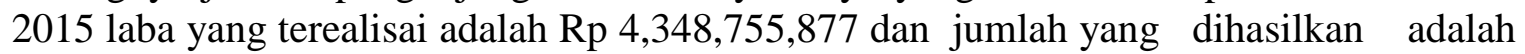
Rp 3,796,350,494. Tahun 2016 jumlah laba yang terealisasi adalah Rp 5,160,098,077 dan jumlah yang dihasilkan adalah $\mathrm{Rp} 4,616,050,431$. Tahun 2017 jumlah laba yang terealisasi adalah Rp 5,241,487,666 dan jumlah yang dihasilkan adalah Rp 3,964,268,375.

c. Break Even Point (titik impas) Hotel Sahid Kawanua Manado pada tahun 2015 adalah sebesar Rp 1,718,254,055 pada tahun 2016 sebesar Rp 1,274,043,460 dan pada tahun 2017 adalah sebesar Rp 1,290,506,486.

d. Margin Of Safety (tingkat keamanan) Hotel Sahid Kawanua Manado tahun 2015 sebesar $54,73 \%$, tahun 2016 sebesar 72,39\% dan tahun 2017 sebesar 67,44\%. Besar penjualan minimal yang diperbolehkan (Margin Of Safety) pada Hotel Sahid Kawanua Manado tahun 2015 sebesar Rp 2,078,096,439 tahun 2016 sebesar Rp 3,342,006,971 tahun 2017 sebesar Rp 5,165,524,076.

\subsection{Saran}

Agar evaluasi pencapain laba dapat terealisasikan Hotel Sahid Kawanua Manado harus memperhatikan biaya variabel. Karena biaya variabel sangat berpengaruh pada besar kecilnya target laba perusahaan dan perlu menekan biaya-biaya variabel tertentu agar tidak 
terjadi pemborosan seperti biaya listrik dan perlengkapan hotel. Pihak perusahaan dapat meminimalisir biaya perlengkapan tersebut dengan berbelanja lebih murah tetapi dengan kualitas yang terjamin.

Semakin besar biaya variabel yang dikelurkan semakin besar pula target laba yang harus dicapai perusahaan. Jika biaya variabel semakin kecil perusahaan akan lebih mudah mencapai target laba.

\section{DAFTAR PUSTAKA}

Ahmad. 2012. "Akuntansi Biaya”. Yogyakarta: Unit Penerbit dan Penecetakan Sekolah Tinggi Ilmu Manajemen YKPN.

Bustami, Bastian. Nurlela. (2013). Akuntansi Biaya: Kajian Teori dan Aplikasi. Yogyakarta: Graha Ilmu.

Baldric, Bambang Suripto, dkk. (2013). Akuntansi Biaya. Edisi 2. Jakarta: Salemba Empat.

Carter dan Usry. (2013). "Akuntansi Biaya”. Edisi Ketigabelas. Buku Satu. Salemba Empat. Jakarta.

Firdaus Ahmad dan Wasilah Abdula. (2012). Akuntasi Biaya. Jakarta: Salemba Empat.

Gilang Mifta Fariz. 2013. "Analisis Cost Volume Profit (CVP) Sebagai Alat Bantu Evaluasi

Pencapaian Laba Pada Hotel Grasia Semarang”. Jurnal Akuntansi. Fakultas Ekonomi dan Bisnis Universitas Dian Nuswantoro Semarang. Hal. 31

Hansen dan Mowen. (2012). Akuntansi Manajerial. Buku 2. Edisi Kedelapan. Jakarta: Salemba Empat.

Jumingan. (2014:183). Analisis Laporan Keuangan. Jakarta : Bumi Aksara.

Kasmir. (2013:333). Analisis Laporan Keuangan. Jakarta: PT Raja. Grafindo Persadu. Rajawali Pers.

Mulyadi. (2015). Akuntansi Biaya. Yogyakarta: Unit Penerbit dan Pencetakan Sekolah Tinggi Ilmu Manajemen YKPN.

Polimeni, Ralph S dan James A., Cashin (2000). Cost Accounting. McGraw Hill. New York.

Sujarweni, Wiranta. (2015). Akuntansi Manajemen. Yogyakarta: Pustaka Baru Perss.

Samryn. 2012. Akuntansi Manajemen: informasi biaya untuk mengendalikan aktivitas operasi dan informasi. Buku Edisi Pertama. Kencana Prenada Media Group. Jakarta. 